Friesema, I.H.M., Koppeschaar, C.E., Donker, G.A., Dijkstra, F., Noort, S.P. van, Smallenburg, R., Hoek, W. van der, Sande, M.A.B. van der. Internet-based monitoring of influenza-like illness in the general population: experience of five influenza seasons in the Netherlands. Vaccine: 2009, 27(45), 6353-6357

\begin{tabular}{|l|l|}
\hline Postprint Version & 1.0 \\
\hline Journal website & $\underline{\text { http://dx.doi.org/10.1016/j.vaccine.2009.05.042 }}$ \\
\hline Pubmed link & $\underline{\text { http://www.ncbi.nlm.nih.gov/pubmed/19840672 }}$ \\
\hline DOI & $10.1016 /$ j.vaccine.2009.05.042 \\
\hline
\end{tabular}

This is a NIVEL certified Post Print, more info at http://www.nivel.eu

\title{
Internet-based monitoring of influenza-like illness in the general population: Experience of five influenza seasons in the Netherlands
}

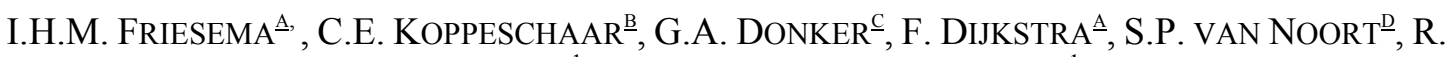 \\ SMALLENBURG $^{\mathrm{B}}$, W. VAN DER HOEK ${ }^{\mathrm{A}}, \underline{1}$ AND M.A.B. VAN DER SANDE ${ }^{\mathrm{A}}, \frac{1}{1}$ \\ ${ }^{a}$ Centre for Infectious Disease Control, National Institute for Public Health and the Environment (RIVM), \\ Bilthoven, The Netherlands \\ ${ }^{\mathrm{b}}$ The Great Influenza Survey/Acquisto Inter BV, Amsterdam, The Netherlands \\ ${ }^{c}$ NIVEL (Netherlands Institute for Health Services Research), Utrecht, The Netherlands \\ ${ }^{\mathrm{d} I n s t i t u t o ~ G u l b e n k i a n ~ d e ~ C i e ̂ n c i a, ~ O e i r a s, ~ P o r t u g a l ~}$
}

\begin{abstract}
Like in most other countries, influenza surveillance in The Netherlands is based upon influenza-like illness (ILI) consultations reported by sentinel general practitioners (GP). In addition, an internet-based monitoring of ILI in the general population started in 2003/2004 (Great Influenza Survey (GIS)). We compared GIS results over 5 influenza seasons with results from the GP system. Weekly ILI incidence from GIS correlated well with ILI incidence from the GP system the same week and even better 1 week later. This suggests that GIS is useful for early detection of trends in influenza activity. However, two important vulnerable groups, children and the elderly, are clearly underrepresented in the GIS. Furthermore, virological confirmation is lacking in the GIS. So, GIS can be a useful addition to the GP system, especially when representativeness can be improved and when participation remains at the current high level.
\end{abstract}

\section{INTRODUCTION}

Almost every winter, an influenza epidemic causes illness with associated increase in medical consumption and excess deaths [1], [2], [3] and [4], in particular among vulnerable persons such as the elderly. Policy makers need rapid reliable data on influenza-like illness (ILI) in the population to be able to detect and respond to both seasonal influenza and pandemic influenza. The traditional surveillance for influenza in most countries relies on both virological and clinical data, often based upon ILI consultations. The surveillance in the Netherlands is based upon weekly ILI consultations data from general practitioners (GP) participating in the Dutch Sentinel Practice Network [5]. This is a nationwide network that covers about $0.8 \%$ of the general population [6]. A sample of the consulting ILI patients is tested for influenza virus $\mathrm{A}$ and $\mathrm{B}$ by nose and throat swabs, and when positive further cultured for typing of the strain.

Besides traditional surveillance systems, new systems have been set up to track ILI in the general population. Traditional health care-based surveillance systems mostly capture young children and the elderly with a more severe presentation of ILI or with a higher risk of complications. A syndromic population surveillance system can provide an early warning of rises in perceived community morbidity, although less specific than a GP network as a medical and microbiological diagnosis is lacking. Furthermore, alternative systems could provide additional information in case sentinel GP networks would come under severe pressure in a pandemic situation. In the United Kingdom, influenza activity is also monitored via calls about cold/flu to NHS Direct, a $24 \mathrm{~h}$ health advice and information telephone service 
Friesema, I.H.M., Koppeschaar, C.E., Donker, G.A., Dijkstra, F., Noort, S.P. van, Smallenburg, R., Hoek, W. van der, Sande, M.A.B. van der. Internet-based monitoring of influenza-like illness in the general population: experience of five influenza seasons in the Netherlands. Vaccine: 2009, 27(45), 6353-6357

with nurse triage [7]. Increase in over-the-counter pharmaceutical sales could be a possible early warning indicator of influenza activity [8]. The ever increasing access to the internet offers new tools for surveillance. The occurrence of influenza showed a strong relationship with queries to online search engines for influenza-related topics [9], [10] and [11]. Since the 2007/2008 influenza season in Sweden, a self-reporting system exists based on a random population-based sample of people invited to report by telephone and internet whenever they experience fever or cold-like symptoms. Out of 10,000 invitations, 4000 respondents joined in Ref. [12].

In the 2003/2004 flu season, the first internet-based monitoring of ILI in the general population started in the Netherlands and Belgium ('de Grote Griepmeting' or Great Influenza Survey (GIS)). Similar projects started in Portugal in 2005 and in Italy in 2007. Information on the three surveys is available at http://www.influenzanet.com. In Australia the comparable Flutracking Project (http://www.flutracking.net) is operating since 2006.

Marquet et al. [13] have evaluated the first season (2003/2004) of the GIS in the Netherlands. They concluded that recruitment of a high number of participants was feasible, and that the results of the GIS followed the results of the Dutch Sentinel Practice Network. The season 2006/2007 was evaluated for the Netherlands, Belgium and Portugal [14]. Also in this comparison, the incidence curves of the internet-based system followed the curves of the European Influenza Surveillance Scheme (EISS). The present study describes the characteristics of the GIS participants and compares the Dutch internet-based data of GIS with the official ILI data from the Dutch Sentinel Practice Network over five winter seasons evaluating reliability and accuracy.

\section{[TABLE 1.]}

\section{MATERIALS AND METHODS}

GIS is an internet-based system monitoring ILI during the winter season. At the beginning of the season, a press release is distributed to encourage a visit of the website and participation in the internet-based surveillance. Participants of the previous season receive an email for participation in the new season. Also during the season, press releases are given out to focus attention at the internet-based system. Any resident of Flanders (Belgium) or the Netherlands may participate after completing an on line questionnaire. This baseline questionnaire contains demographical, medical, and lifestyle questions. On a weekly basis, participants receive an email with a link to a short symptom questionnaire asking about cough, running nose, headache, sore throat, chest pain, muscle pain, diarrhea, abdominal pain, cold shivers, and irritated eyes since their previous visit to the website. The participant is also asked for the highest body temperature (if measured) and if fever was observed with or without sudden onset. In case symptoms are reported, the participant is also requested to report whether or not a GP was consulted, and whether or not daily activities were adjusted due to the symptoms. Data of the Netherlands only were used for the present analysis.

Representativeness of the GIS participants was assessed by comparing the characteristics of the participants with those of the Dutch general population. Age and sex distribution, and percentage (self)employed (only when aged between 15 and 64 years) within GIS were compared with data from Statistics Netherlands [15] and [16]. Coverage of influenza vaccination and prevalence of diabetes, were compared with data from the Netherlands Information Network of General Practice (LINH) [17], [18], [19], [20], [21] and [22].

\section{[FIG. 1.]}

ILI was defined as sudden onset of fever $\left(\geq 38.0^{\circ} \mathrm{C}\right)$ accompanied by muscle pain, and cough and/or sore throat and/or chest pain. The day of onset of fever determines the onset of ILI. Incidence of ILI was calculated per week (Monday-Sunday). ILI reported within 2 weeks after day of onset was included in the analyses. A recurrent episode of ILI was only counted when the participant had reported at least 1 week without ILI between both episodes. Incidence was computed by dividing the number of participants with ILI in a particular week by the total number of reporting participants in the same week. If a participant had responded more than 1 time in a week, he was counted only once. These incidence figures were compared with the incidence rates as estimated from ILI consultations in the sentinel GP network. For the comparison Pearson correlation coefficients were calculated for each influenza season for the total group, and separately for the five age groups $0-4,5-14,15-44,45-64$, and $>64$ years. 
Friesema, I.H.M., Koppeschaar, C.E., Donker, G.A., Dijkstra, F., Noort, S.P. van, Smallenburg, R., Hoek, W. van der, Sande, M.A.B. van der. Internet-based monitoring of influenza-like illness in the general population: experience of five influenza seasons in the Netherlands. Vaccine: 2009, 27(45), 6353-6357

\section{RESULTS}

In total, 50,951 persons participated during one or more of the five influenza seasons. Almost half of them (49\%) participated one season, $21 \%$ two seasons, $12 \%$ three seasons, $9 \%$ four seasons, and $8 \%$ participated all five seasons. Each winter season, around 20,000 volunteers participated (Table 1). Mean participation per person per season almost doubled from 8.3 weekly reports in 2003/2004 to 17.6 weekly reports in $2007 / 2008$. As the number of weeks per season was not equal over the 5 years, also the mean number of reports per week was calculated showing a similar pattern. Each season, between $60 \%$ and $67 \%$ participated at least half the season, except for the first season (2003/2004: 36\%; Fig. 1). About 10\% reported only 1 week (2003/2004: 21\%). The proportion of participants with ILI visiting a GP increased slightly over the 5year period, from $17.9 \%$ in $2003 / 2004$ to $22.6 \%$ in $2007 / 2008$. Overall, young children and the elderly went more often to a GP when experiencing ILI than the older children and adults (Table 2). Most participants stay at home when they have ILI (86.1-89.3\%).

\section{[TABLE 2.]}

The age distribution within the GIS did not follow the age distribution of the general Dutch population (Table 2). Children, especially those younger than 5 years, and the elderly are underrepresented in the GIS. Furthermore, participation of children appears to decline over the years, whereas participation of the adults, especially in the age group 45-64 years, increases. In $2003 / 2004,47.3 \%$ of the participants was male. In the following years, this percentage was between $43.0 \%$ and $43.9 \%$. The percentage of males in the general population in the same period was $49.5 \%$. Overall, the percentage of (self-)employed volunteers approaches the situation in the general population. Only participants aged 15-24 years work less often than in the general Dutch population.

Vaccination uptake among the GIS participants younger than 45 years of age was about twice that of the general Dutch population (Table 2). Only vaccination rates in the oldest age group were similar. Prevalence of diabetes was somewhat higher in the GIS participants younger than 45, and lower in the GIS participants older than 64 years of age. Overall, prevalence of diabetes was comparable between GIS and the general population.

Incidence of ILI in the GIS was about 10 times higher than the ILI consultation rates. However, both surveillance systems show a comparable course over time of ILI (Fig. 2). Correlations between incidence estimates from GIS and the sentinel GP system were fairly high for all 5 years, except for 2003/2004 (Table 3). Furthermore, incidence figures from GIS correlate better with incidence rates from the GP system 1 week later than with those of the same week, especially for age groups under 45 years. No results are shown for the age group 0-4 years, as this group was too small in GIS for reliable incidence estimates. Lowest correlations were found for the elderly.

\section{[FIG. 2.]TABLE 3.]}

\section{DISCUSSION}

The GIS started in the autumn of 2003 with every year a participation of more than 20,000 residents of the Netherlands. Via the GP sentinel network about $0.8 \%$ of the Dutch population is being monitored. The GP network covered 135,400 Dutch inhabitants in 2007 [6]. The weekly questionnaire consists of more symptoms than needed for defining ILI episodes, which makes the system flexible for changes in definition and detection of changes in reported symptoms, and useful for other (related) syndromes. If a strong need exists, symptoms could be added to the questionnaire rapidly.

Participants of GIS were compared to the general Dutch population on several variables. Children and the elderly were clearly underrepresented in GIS. As ILI, and influenza virus infection with its complications, is most common in these age-groups, GIS will underestimate the overall incidence rates. Nevertheless, adults visit their GP less promptly than children and the elderly when having ILI, causing an underestimation of the incidence rate of the adult group within the sentinel network. The elderly participants were also healthier than the average Dutch senior, which probably led to the weak correlations between the incidences of GIS and the sentinel network in this age group. Non-participation of the elderly may be due to their limited use of the internet. In 2005, 64\% of Dutch inhabitants aged between 65 and 75 years did never use internet, and although this percentage is decreasing, it was still 52\% in 2007 [23]. In 
Friesema, I.H.M., Koppeschaar, C.E., Donker, G.A., Dijkstra, F., Noort, S.P. van, Smallenburg, R., Hoek, W. van der, Sande, M.A.B. van der. Internet-based monitoring of influenza-like illness in the general population: experience of five influenza seasons in the Netherlands. Vaccine: 2009, 27(45), 6353-6357

comparison, almost all young people (12-25 years) and at least $90 \%$ of the group aged $25-45$ years used internet in the preceding 3 months. Nevertheless, use of internet will probably only increase, especially in the elderly groups, as the younger users will get older. Participants aged 15-24 were less often selfemployed than in the Dutch population, possibly because of a higher participant rate among students. The higher vaccination uptake among the participants younger than 45 years of age could be an indicator of a relative high sense of health and healthy behaviour in this group or of a group who has more often underlying diseases than in the general population. One option to improve representativeness would be to invite a random sample of the population to participate in the GIS. Useful information would also be obtained by a non-response analysis. A comparison that was not made, are the costs of both systems. Especially when expanding a surveillance network, surveying and comparing all costs should be done.

The overall incidences from GIS data correlated well with those from the sentinel network, except for the first season. When using only participants who replied at least 5 times to weekly e-mails and leaving out the first report of each participant, incidences of GIS and the GPs follow an almost similar curve during this first season [13]. This shows that short-term participants can bias the results. The correlations increased when using a 1 week lag time between the GIS incidences and the incidences from the sentinel network. This suggests that GIS may even detect changes in incidences a week earlier than the GPs. An explanation could be that most people will not go to the GP on the first day that they fall ill, while in GIS this first illness day is reported. In case of real time monitoring this implies that the volunteers will have to report ILI within 1 week. Nevertheless, separate analyses of ILI reports done within 1 week resulted in differences in incidence level, but not in trends (data not shown). In case of a pandemic, it is unclear whether this will affect the reporting behaviour of the volunteers. One could hypothesize that if the media pay a lot of attention to influenza, volunteers will be more inclined to report symptoms, resulting in an overestimation or even a false alarm. Overall, a key role for GPs will probably lead to a higher level of continuity and scrutiny.

Another limitation of GIS is the lack of medical or laboratory confirmation of diagnosis. A GP was consulted in about 1 in 5 GIS reported ILI episodes, but ILI incidence was 10 times higher in GIS compared to the sentinel network. GPs will be more critical in making the diagnosis. In direct contact with the patient, the GP can exclude other diseases than ILI. The incidence of medically confirmed ILI consultations will therefore be lower than self-reported ILI in GIS. In a Dutch study in 1991-1992, it was estimated for the elderly (60 years or older) that the incidence in the community was 4-6 times higher than reported by GP sentinel stations [24]. Furthermore, from a sample of the ILI patients in the sentinel network nose and throat swabs are taken and tested for influenza virus [25]. In a population-based setting, self-sampling would be the easiest and cheapest way of virological testing. A group of 294 callers to the United Kingdom national telephone health helpline (NHS direct) mentioning colds or flu were sent a self-sampling kit [26]. They were asked to swab both nostrils. These swabs were then tested for influenza virus. About half the callers sent back the samples, and the average time between the call and the results of the laboratory was 7 days. The overall influenza-positive rate $(16 \%)$ was lower than in the national virological surveillance of the UK (26\%). Response rates were highest for callers aged 45 years or older. Finally, the majority of the participants did not experience problems in taking the test. The possibility of self-sampling in internetbased surveillance systems should be explored.

In 2009, EPIWORK, an EU-funded research project started building a new, comprehensive, epidemic forecasting infrastructure in Europe. Key instrument providing the real-time disease incidence data collection for this infrastructure will be the GIS modelled, internet-based monitoring system which is going to operate in Sweden, Germany, UK, France and Spain, in addition to the Netherlands, Belgium, Portugal and Italy.

In conclusion, the size of the group of participants and the use of a weekly symptom questionnaire are clear advantages of GIS. Furthermore, GIS seems useful for early detection of changes in ILI incidence. Nevertheless, GIS participants are not representative for the Dutch population. Therefore, efforts should be made to gain more insight in the characteristics of the participants, and to improve the representativeness. It is unknown what effect a pandemic will have on GIS and its participants, but it might be a useful addition to the sentinel GP system when the regular health system is under stress in a pandemic situation. 
Friesema, I.H.M., Koppeschaar, C.E., Donker, G.A., Dijkstra, F., Noort, S.P. van, Smallenburg, R., Hoek, W. van der, Sande, M.A.B. van der. Internet-based monitoring of influenza-like illness in the general population: experience of five influenza seasons in the Netherlands. Vaccine: 2009, 27(45), 6353-6357

\section{REFERENCES}

[1] L. Simonsen, M.J. Clarke, G.D. Williamson, D.F. Stroup, N.H. Arden and L.B. Schonberger, The impact of influenza epidemics on mortality: introducing a severity index, Am J Pub Health 87 (12) (1997), pp. 1944-1950.

[2] W.W. Thompson, D.K. Shay, E. Weintraub, L. Brammer, C.B. Bridges and N.J. Cox et al., Influenzaassociated hospitalizations in the United States, JAMA 292 (11) (2004), pp. 1333-1340.

[3] W.W. Thompson, D.K. Shay, E. Weintraub, L. Brammer, N. Cox and L.J. Anderson et al., Mortality associated with influenza and respiratory syncytial virus in the United States, JAMA 289 (2) (2003), pp. 179-186.

[4] A.G.S.C. Jansen, E.A.M. Sanders, A.W. Hoes, A.M. Van Loon and E. Hak, Influenza- and respiratory syncytial virus-associated mortality and hospitalisations, Eur Resp J 30 (6) (2007), pp. 1158-1166.

[5] J.C. De Jong, G.F. Rimmelzwaan, G.A. Donker, A. Meijer and R.A.M. Fouchier, Osterhaus ADME. Het influenzaseizoen 2006/'07 in Nederland en de vaccinsamenstelling voor het seizoen 2007/'08, Ned Tijdschr Geneeskd 151 (39) (2007), pp. 2158-2165.

[6] G.A. Donker, Continue morbiditeits registratie peilstations Nederland 2007, Nivel, Utrecht (2008).

[7] G.E. Smith, D.L. Cooper, P. Loveridge, F. Chinemana, E. Gerard and N. Verlander, A national syndromic surveillance system for England and Wales using calls to a telephone helpline, Euro Surveill 11 (12) (2006), pp. 220-224.

[8] S.F. Magruder, Evaluation of over-the-counter pharmaceutical sales as a possible early warning indicator of human disease 24, Johns Hopkins APL Technical Digest (Applied Physics Laboratory) (2003) (4):pp. 349-53.

[9] G. Eysenbach, Infodemiology: tracking flu-related searches on the web for syndromic surveillance, AMIA (2006), pp. 244-248.

[10] P.M. Polgreen, Y. Chen, D.M. Pennock and F.D. Nelson, Using internet searches for influenza surveillance, Clin Infect Dis 47 (11) (2008), pp. 1443-1448.

[11] J. Ginsberg, M.H. Mohebbi, R.S. Patel, L. Brammer, M.S. Smolinski and L. Brilliant, Detecting influenza epidemics using search engine query data, Nature 457 (2008), pp. 1012-1014.

[12] Public health development-seasonal influenza.

http://ecdc.europa.eu/en/health_content/phdev/090115_ph.aspx. Access date 23 February 2009.

[13] R.L. Marquet, A.I.M. Bartelds, S.P. Van Noort, C.E. Koppeschaar, J. Paget and F.G. Schellevis et al., Internet-based monitoring of influenza-like illness (ILI) in the general population of the Netherlands during the 2003-2004 influenza season, BMC Public Health 6 (2006), p. 242.

[14] S.P. van Noort, M. Muehlen, H. Rebelo de Andrade, C. Koppeschaar, J.M. Lima Lourenco and M.G. Gomes, Gripenet: an internet-based system to monitor influenza-like illness uniformly across Europe, Euro Surveill 12 (7) (2007) pii $=722$.

[15] Population; age, sex, marital status on 1 January. http://statline.cbs.nl/statweb/. Access date 13 November 2008.

[16] Working population by sex. http://statline.cbs.nl/statweb/. Access date 13 November 2008.

[17] M. Tacken, R. Verheij, J. Mulder, H. Van den Hogen and J. Braspenning, Monitoring Griepvaccinatiecampagne 2003, NIVEL, Nijmegen/Utrecht (2004).

[18] M. Tacken, R. Verheij, J. Mulder, H. van den Hogen and J. Braspenning, Monitoring Griepvaccinatiecampagne 2004, NIVEL, Nijmegen/Utrecht (2005).

[19] M. Tacken, R. Verheij, J. Mulder, H. van den Hogen and J. Braspenning, Monitoring Griepvaccinatiecampagne 2005, NIVEL, Nijmegen/Utrecht (2006).

[20] M. Tacken, B. Mulder, H. van den Hogen, J. Donkers, W. Tiersma and R. Verheij et al., Monitoring Griepvaccinatiecampagne 2006, LINH, Nijmegen/Utrecht (2007).

[21] M. Tacken, J. Mulder, H. Van den Hogen, W. Tiersma, R. Verheij and J. Braspenning, Monitoring nationaal programma Grieppreventie 2007, LINH, Nijmegen/Utrecht (2008).

[22] Incidentie- en prevalentiecijfers. http://www.linh.nl. Access date 13 January 2009.

[23] ICT gebruik van personen naar persoonskenmerken. http://statline.cbs.nl/statweb/. Access date 19 November 2008.

[24] T.M.E. Govaert, Thijs CTMCN, N. Masurel, M.J.W. Sprenger, G.J. Dinant and J.A. Knottnerus, The efficacy of influenza vaccination in elderly individuals: a randomized double-blind placebo-controlled trial, JAMA 272 (21) (1994), pp. 1661-1665.

[25] A.I.M. Bartelds, Continuous morbidity registration at Dutch Sentinel Stations in 2003, Nivel, Utrecht (2004). 
Friesema, I.H.M., Koppeschaar, C.E., Donker, G.A., Dijkstra, F., Noort, S.P. van, Smallenburg, R., Hoek, W. van der, Sande, M.A.B. van der. Internet-based monitoring of influenza-like illness in the general population: experience of five influenza seasons in the Netherlands. Vaccine: 2009, 27(45), 6353-6357

[26] D.L. Cooper, G.E. Smith, F. Chinemana, C. Joseph, P. Loveridge and P. Sebastionpillai et al., Linking syndromic surveillance with virological self-sampling, Epidemiol Infect 136 (2) (2008), pp. 222-224.

\section{TABLES}

Table 1

Great influenza survey (GIS) results from 2003/2004 to 2007/2008.

\begin{tabular}{|c|c|c|c|c|c|}
\hline Characteristics & $2003 / 2004$ & $2004 / 2005$ & $2005 / 2006$ & $2006 / 2007$ & $2007 / 2008$ \\
\hline Week numbers included & $44-15$ & $46-18$ & $44-18$ & $48-18$ & $42-18$ \\
\hline Number of participants & 21,299 & 19,287 & 22.520 & 19,582 & 22,063 \\
\hline$\%$ of participants with ILI & $11.6 \%$ & $11.8 \%$ & $7.6 \%$ & $7.4 \%$ & $9.0 \%$ \\
\hline Number of weekly reports & 176,802 & 286,972 & 362,618 & 305.489 & 387.855 \\
\hline Number of weekly reports per participant & 8.3 & 14.9 & 16.1 & 15.6 & 17.6 \\
\hline Mean number of reports per week & 7367 & 11,479 & 13,430 & 13.282 & 13,374 \\
\hline Number of ILI reports & 2280 & 2232 & 1765 & 1431 & 1971 \\
\hline$\%$ of ILI patients staying home & $89.3 \%$ & $88.5 \%$ & $86.2 \%$ & $86.1 \%$ & $88.0 \%$ \\
\hline
\end{tabular}

Fig. 1. Cumulative percentage of participants by number of weeks reported during an influenza season.

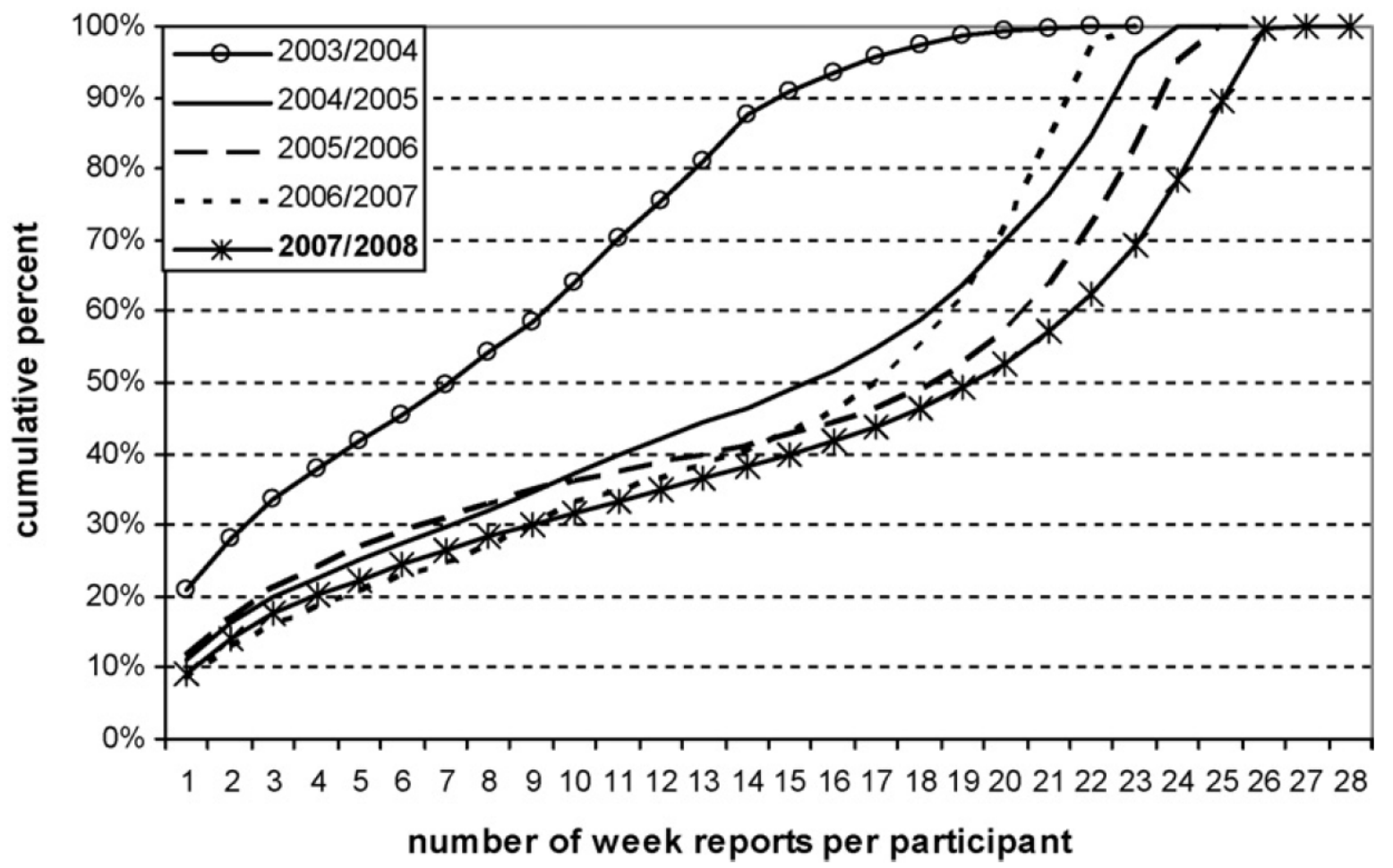


Friesema, I.H.M., Koppeschaar, C.E., Donker, G.A., Dijkstra, F., Noort, S.P. van, Smallenburg, R., Hoek, W. van der, Sande, M.A.B. van der. Internet-based monitoring of influenza-like illness in the general population: experience of five influenza seasons in the Netherlands. Vaccine: 2009, 27(45), 6353-6357

Table 2

Characteristics of the GIS participants per influenza season compared to the Dutch general population [15-22].

\begin{tabular}{|c|c|c|c|c|c|c|}
\hline Age & 2003/2004 & $2004 / 2005$ & $2005 / 2006$ & $2006 / 2007$ & $2007 / 2008$ & Dutch population \\
\hline \multicolumn{6}{|l|}{ Age distribution } & Mean (range 2003-2008) \\
\hline $0-4$ years & $1.5 \%$ & $0.8 \%$ & $0.7 \%$ & $0.6 \%$ & $0.5 \%$ & $6.1 \%(5.8-6.3)$ \\
\hline $5-14$ years & $12.3 \%$ & $6.1 \%$ & $4.2 \%$ & $2.9 \%$ & $2.5 \%$ & $12.2 \%(12.1-12.3)$ \\
\hline $15-44$ years & $53.1 \%$ & $52.3 \%$ & $53.8 \%$ & $50.7 \%$ & $51.1 \%$ & $41.2 \%(40.1-42.4)$ \\
\hline $45-64$ years & $28.2 \%$ & $34.1 \%$ & $34.8 \%$ & $38.0 \%$ & $38.1 \%$ & $26.3 \%(25.3-27.3)$ \\
\hline 65 or older & $5.0 \%$ & $6.8 \%$ & $6.6 \%$ & $7.8 \%$ & $7.8 \%$ & $14.2 \%(13.7-14.7)$ \\
\hline \multicolumn{6}{|c|}{ Working population per age group } & Mean (range 2003-2007) \\
\hline $15-64$ years & $60.2 \%$ & $67.4 \%$ & $68.9 \%$ & $70.5 \%$ & $72.0 \%$ & $72.9 \%(71.8-74.8)$ \\
\hline $15-24$ years & $23.1 \%$ & $28.0 \%$ & $33.7 \%$ & $36.6 \%$ & $38.5 \%$ & $66.1 \%(64.2-68.2)$ \\
\hline $25-44$ years & $74.9 \%$ & $80.6 \%$ & $82.0 \%$ & $82.7 \%$ & $84.0 \%$ & $84.2 \%(83.2-86.2)$ \\
\hline $45-64$ years & $62.4 \%$ & $68.2 \%$ & $67.8 \%$ & $67.9 \%$ & $69.1 \%$ & $63.3 \%(61.9-65.8)$ \\
\hline \multicolumn{6}{|c|}{ Diabetes prevalence per age group } & Range 2003-2007 \\
\hline 5-14 years & $1.5 \%$ & $0.9 \%$ & $0.3 \%$ & $0.5 \%$ & $0.9 \%$ & $0.11-0.15 \%$ \\
\hline $15-24$ years & $0.6 \%$ & $0.7 \%$ & $0.9 \%$ & $1.0 \%$ & $1.4 \%$ & $0.16-0.22 \%$ \\
\hline $25-44$ years & $1.4 \%$ & $1.3 \%$ & $1.4 \%$ & $1.4 \%$ & $1.5 \%$ & $0.69-0.86 \%$ \\
\hline 45-64 years & $4.4 \%$ & $4.9 \%$ & $5.5 \%$ & $5.9 \%$ & $6.3 \%$ & $4.6-5.9 \%$ \\
\hline 65 or older & $9.2 \%$ & $11.4 \%$ & $10.6 \%$ & $11.9 \%$ & $10.5 \%$ & $11.5-14.8 \%$ \\
\hline 5 or older & $9.6 \%$ & $11.9 \%$ & $13.0 \%$ & $17.2 \%$ & $17.4 \%$ & $13.7-17.9 \%$ \\
\hline Total & $2.5 \%$ & $3.1 \%$ & $3.3 \%$ & $4.0 \%$ & $4.1 \%$ & $3.15-4.17 \%$ \\
\hline \multicolumn{6}{|c|}{ Vaccination coverage per age group } & Mean (range 2003-2007) \\
\hline $0-4$ years & $4.8 \%$ & $6.2 \%$ & $8.8 \%$ & $2.7 \%$ & $4.8 \%$ & $2.4 \%(2.1-3.0)$ \\
\hline $5-14$ years & $15.4 \%$ & $11.2 \%$ & $8.7 \%$ & $7.0 \%$ & $7.8 \%$ & $5.2 \%(4.9-5.6)$ \\
\hline $15-44$ years & $10.1 \%$ & $11.1 \%$ & $14.0 \%$ & $14.7 \%$ & $12.2 \%$ & $5.0 \%(4.8-5.4)$ \\
\hline $45-64$ years & $23.4 \%$ & $25.1 \%$ & $30.8 \%$ & $31.8 \%$ & $29.2 \%$ & $18.7 \%(17.0-20.7)$ \\
\hline 65 or older & $79.7 \%$ & $79.3 \%$ & $83.7 \%$ & $81.6 \%$ & $77.8 \%$ & $79.1 \%(77.4-80.7)$ \\
\hline Total & $17.9 \%$ & $20.5 \%$ & $24.1 \%$ & $26.1 \%$ & $23.2 \%$ & $17.9 \%(17.5-18.6)$ \\
\hline \multicolumn{7}{|c|}{ Visit of GP during ILI episode per age group } \\
\hline $0-4$ years & $39.4 \%$ & $35.7 \%$ & $9.5 \%$ & $26.7 \%$ & $42.9 \%$ & \\
\hline $5-14$ years & $18.1 \%$ & $23.8 \%$ & $26.4 \%$ & $22.8 \%$ & $20.2 \%$ & \\
\hline $15-44$ years & $16.5 \%$ & $18.3 \%$ & $21.0 \%$ & $19.4 \%$ & $22.2 \%$ & \\
\hline $45-64$ years & $18.0 \%$ & $18.5 \%$ & $22.0 \%$ & $25.5 \%$ & $22.3 \%$ & \\
\hline 65 or older & $24.1 \%$ & $30.4 \%$ & $24.6 \%$ & $37.8 \%$ & $30.9 \%$ & \\
\hline Total & $17.9 \%$ & $19.3 \%$ & $21.6 \%$ & $22.3 \%$ & $22.6 \%$ & \\
\hline
\end{tabular}

Table 3

Correlations between ILI incidence as estimated from GIS and the GP sentinel network within the same week and with a lag time of 1 week by influenza season.

\begin{tabular}{|c|c|c|c|c|c|}
\hline Comparison & $2003 / 2004$ & $2004 / 2005$ & $2005 / 2006$ & $2006 / 2007$ & $2007 / 2008$ \\
\hline \multicolumn{6}{|l|}{ All ages } \\
\hline GIS vs. GP. same week & 0.420 & 0.656 & 0.888 & 0.759 & 0.771 \\
\hline GIS vs. GP 1 week later & 0.681 & 0.879 & 0.896 & 0.872 & 0.817 \\
\hline \multicolumn{6}{|l|}{ Aged 5-14 years } \\
\hline GIS vs. GP, same week & 0.459 & 0.690 & 0.501 & 0.746 & 0.616 \\
\hline GIS vs. GP 1 week later & 0.660 & 0.835 & 0.611 & 0.646 & 0.728 \\
\hline \multicolumn{6}{|l|}{ Aged $15-44$ years } \\
\hline GIS vs. GP, same week & 0.354 & 0.565 & 0.736 & 0.636 & 0.701 \\
\hline GIS vs. GP 1 week later & 0.677 & 0.803 & 0.913 & 0.757 & 0.769 \\
\hline \multicolumn{6}{|l|}{ Aged 45-64 years } \\
\hline GIS vs. GP. same week & 0.650 & 0.619 & 0.486 & 0.619 & 0.441 \\
\hline GIS vs. GP 1 week later & 0.721 & 0.860 & 0.540 & 0.652 & 0.435 \\
\hline \multicolumn{6}{|l|}{ Aged 65 or older } \\
\hline GIS vs. GP, same week & 0.361 & 0.480 & 0.023 & 0.458 & 0.108 \\
\hline GIS vs. GP 1 week later & 0.468 & 0.802 & 0.372 & 0.476 & 0.025 \\
\hline
\end{tabular}


Friesema, I.H.M., Koppeschaar, C.E., Donker, G.A., Dijkstra, F., Noort, S.P. van, Smallenburg, R., Hoek, W. van der, Sande, M.A.B. van der. Internet-based monitoring of influenza-like illness in the general population: experience of five influenza seasons in the Netherlands. Vaccine: 2009, 27(45), 6353-6357

Fig. 2. Incidence of ILI measured by GIS (per 1000 participants) and the GP sentinel network (GP; per 10,000 inhabitants) during the influenza season 2007/2008.

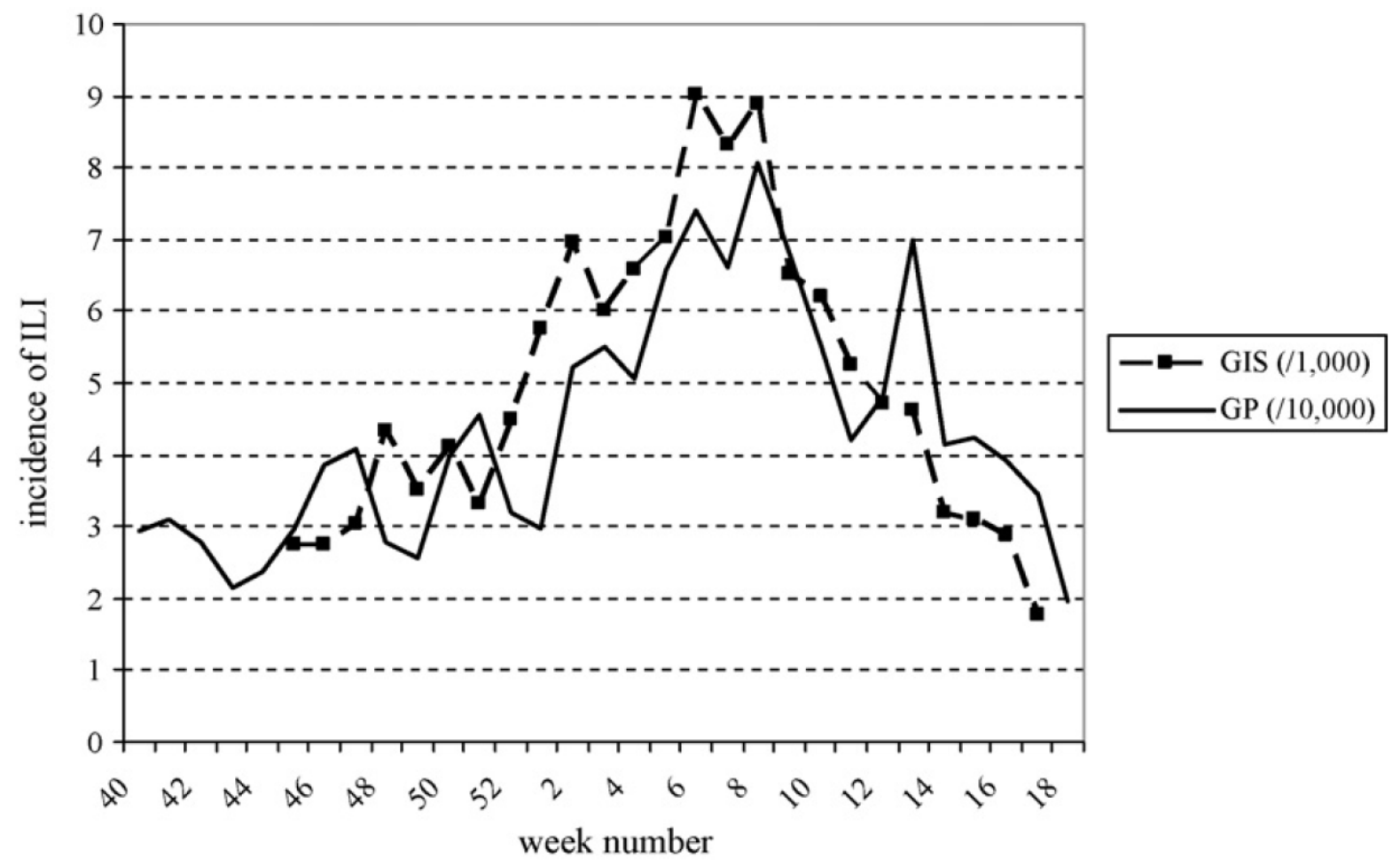

